\title{
Pengaruh Pelatihan Komunikasi ISOBAR (Identify, Situation, Observations, Background, Assesment, Recommendation) Terhadap Pengetahuan dan Kualitas Pelaksanaan Timbang terima di RSUD Padang Pariaman
}

\author{
Candra Deni Mairosa ${ }^{\mathrm{a}}$, Rizanda Machmud ${ }^{\mathrm{b}}$, Jafril $^{\mathrm{c}}$ \\ ${ }^{a}$ RSUD Padang Pariaman, Pariaman, 25584, Indonesia \\ ${ }^{\text {b}}$ Fakultas Keperawatan Universitas Andalas, Kota Padang, 25163, Indonesia \\ cRSUP M Djamil Padang, Kota Padang, 25171, Indonesia \\ e-mail korespondensi: candradeni290581@gmail.com
}

\begin{abstract}
Handover communication is the transfer of information related to the patient for the continuity of care provided. Errors in the transfer of patient information can result in negligence of treatment, inadequate care and death, for this reason a communication framework is needed so that the information conveyed is fast, precise and accurate. ISOBAR is an operative communication framework that is more structured, complete and accurate so that it can support patient safety. This study aims to identify the effect of ISOBAR communication training for the knowledge and quality of handover in Padang Pariaman District Hospital. This research used a quasy experimental Pre-Post Test with Control Group design. The technique of taking samples was systematic random sampling. The sample in this study was the team leader and the person in charge of the shift with a total of 23 intervention groups and 18 control groups. Data collection is done by questionnaire and observation. Analysis of the data used is the Mann-Whitney statistical test to see differences in the intervention and control groups. The results of this study prove that there is an influence of ISOBAR communication training on knowledge ( $p=$ $0,000)$ and the quality of handover $(p=0,000)$ in the intervention group. It is expected that the Hospital can use ISOBAR communication in handover to improve the quality of human resources and make policies regarding the application of ISOBAR communication in an effort to improve patient safety
\end{abstract}

Keywords: Communication, documentation completeness, handover quality, ISOBAR

\begin{abstract}
Abstrak
Komunikasi timbang terima merupakan transfer informasi terkait pasien untuk kesinambungan asuhan yang diberikan. Kesalahan dalam transfer informasi pasien dapat mengakibatkan kelalaian pengobatan, asuhan tidak tepat dan kematian, untuk itu perlu kerangka komunikasi agar informasi yang disampaikan cepat, tepat dan akurat. ISOBAR merupakan kerangka komunikasi timbang terima yang lebih terstruktur, lengkap dan akurat sehingga menunjang keselamatan pasien. Penelitian ini bertujuan untuk mengidentifikasi pengaruh pelatihan komunikasi ISOBAR terhadap pengetahuan dan kualitas pelaksanaan timbang terima di RSUD Padang Pariaman. Penelitian ini adalah penelitian kuantitatif dengan desain quasy experimental Pre - Post Test with Control Group. Teknik pengambilan sampel adalah systematik random sampling. Sampel pada penelitian ini adalah ketua tim perawat dan penanggung jawab shift dengan jumlah 23 kelompok intervensi dan 18 kelompok kontrol. Pengumpulan data dilakukan dengan kuisioner dan observasi. Analisa data yang digunakan adalah uji statistik Mann-Whitney untuk melihat perbedaan kelompok intervensi dan kontrol. Hasil penelitian ini membuktikan bahwa terdapat pengaruh pelatihan komunikasi ISOBAR terhadap pengetahuan $(\mathrm{p}=0,000)$ dan kualitas pelaksanan timbang terima $(\mathrm{p}=0,000)$ pada kelompok intervensi. Diharapkan pihak Rumah Sakit dapat menggunakan komunikasi ISOBAR untuk meningkatkan proses timbang terima perawat dan membuat kebijakan tentang penerapan komunikasi ISOBAR dalam upaya meningkatkan keselamatan pasien
\end{abstract}

Kata kunci: ISOBAR, komunikasi, kualitas timbang terima, kelengkapan dokumentasi 


\section{PENDAHULUAN}

Komunikasi efektif merupakan hal penting dalam upaya meningkatkan keselamatan pasien. Dalam Standar Nasional Akreditasi Rumah Sakit (SNARS) edisi I tahun 2018, Sasaran Keselamatan Pasien yang kedua adalah meningkatkan komunikasi yang efektif (KARS, 2017). Komunikasi tidak efektif dapat menyebabkan terjadinya insiden keselamatan pasien (Lee, 2015). Data dari IOM (Institute of Medicine) ditemukan 98.000 orang meninggal akibat kesalahan medis dan $2,9 \%-3,7 \%$ pasien rawat inap mengalami insiden keselamatan pasien (Güneş, et. all, 2016). Data KKPRS (Komite Keselamatan Pasien Rumah Sakit) Insiden keselamatan pasien yang ditemukan di Indonesia pada tahun 2006 2011 sebanyak 911 insiden (Putra, 2013). Hal ini menunjukkan masih tingginya insiden keselamatan pasien yang salah satunya dapat disebabkan karena komunikasi yang tidak efektif.

Salah satu bentuk komunikasi efektif adalah komunikasi saat melaksanakan timbang terima yang merupakan transfer informasi dan tanggung jawab profesional untuk kelanjutan perawatan pasien. Komunikasi efektif saat timbang terima dapat meningkatkan kolaborasi, waktu pelaksanaan dapat diminimalkan dan informasi yang disampaikan lebih akurat. Hal ini sejalan dengan penelitian Sohi et al, (2015) dimana komunikasi efektif mengurangi durasi pelaksanaan timbang terima. Dengan demikian penggunaan komunikasi efektif dalam pelaksanaan timbang terima, dapat menghemat waktu dan informasi yang disampaikan menjadi lebih lengkap untuk kontinuitas perawatan dan pengobatan pasien.

Timbang terima (handover) merupakan transfer informasi dan tanggung jawab dari satu penyedia layanan ke penyedia layanan lain Dalam Abdurrahman and Garcia, (2016) timbang terima merupakan proses menyampaikan informasi pasien dan transfer tanggung jawab antar pemberi layanan. Timbang terima dapat dilakukan seperti : timbang terima antar shift, timbang terima antar unit keperawatan, timbang terima antar unit rawatan dengan unit pemeriksaaan diagnostik, timbang terima dengan bagian obat-obatan dan timbang terima antar fasilitas kesehatan. Jadi timbang terima merupakan transfer informasi dan tanggung jawab antar pemberi layanan, antar profesi dan antar unit layanan.

Dari beberapa penelitian menunjukkan bahwa komunikasi SBAR dapat meningkatkan efektivitas pelaksanaan serah terima dan keselamatan pasien. Eggins \& Slade (2015) mengemukakan kerangka komunikasi pelaksanaan timbang terima yang direkomendasikan adalah SBAR, ISBAR dan ISOBAR. Dan Porteous et al, (2009) mengemukakan bahwa kerangka ISOBAR merupakan pengembangan dari kerangka SBAR agar kerangka komunikasi menjadi lebih lengkap.

Compton et al, (2012) mengemukakan bahwa komunikasi SBAR hanya berdasarkan situation, background, assessment, recommendation, dan ISOBAR terdiri dari identify, situation, observations, background, assessment, recommendation. Oleh karena itu Australian Commission on Safety and Quality in Healthcare, (2012) mengemukan bahwa ISOBAR merupakan kerangka timbang terima yang lebih lengkap dan diikuti dengan pemeriksaaan keselamatan pasien pada akhir pelaksanaan timbang terima

Penelitian ini menggunakan kerangka komunikasi ISOBAR dalam pelaksanaan timbang terima yang terdiri dari I (identify untuk mengidentifikasi pasien), $\quad \mathrm{S}$ (Situation menyampaikan kondisi terkini pasien), O (Observations yaitu mengobservasi keadaan pasien), B (Backgroud menjelaskan penyebab masalah dan riwayat penyakit), A (Assesment yaitu penilaian terhadap 
kondisi pasien) $\mathrm{R}$ (Recomendation merupakan penyampaian saran/ tindakan yang akan dilakukan dan mengkonfirmasi informasi yang disampaikan). Dan metode pelatihan yang digunakan berupa seminar, role-play dan bimbingan yang merupakan penggabungan tiga metode pelatihan sehingga responden lebih paham dan mampu dalam mengaplikasikan komunikasi ISOBAR dalam pelaksanaan operan.

Timbang terima bertujuan untuk menjaga kontinuitas asuhan dan menjamin mutu layanan. Joint Communication International (JCI) mewajibkan standar komunikasi dalam pelaksanaan timbang terima dan rumah sakit bebas menetapkan standar sesuai dengan kondisinya masingmasing (Wheeler, 2015). Timbang terima yang tidak efektif dapat menimbulkan beberapa masalah dalam pelayanan keperawatan di rumah sakit seperti kurangnya informasi yang disampaikan, salah persepsi, isi yang disampaikan tidak fokus terhadap masalah pasien, kesalahan dan keterlambatan pengobatan, kematian, infeksi nosokomial, penundaan pelaporan kritis, ketidaksinambungan asuhan, perawatan yang tidak tepat dan penambahan waktu perawatan (AHRQ, 2014, Mardis et al, 2015). Sementara National Clinical Effectiveness Commitee, (2014) meyampaikan Informasi yang kurang tepat saat timbang terima dapat menyebakan potensial terjadinya cidera, untuk itu perlu ditetapkan kerangka komunikasi efektif dalam timbang terima.

RSUD Padang Pariaman merupakan satu-satunya rumah sakit di kabupaten Padang Pariaman. Rumah Sakit rujukan dari 25 puskesmas yang ada di wilayah Kabupaten Padang Pariaman, dengan empat pelayanan dasar rawat inap yaitu rawat inap bedah, non bedah, kebidanan dan anak. Data indikator mutu pelayanan selama tiga tahun terakhir didapatkan parameter keselamatan pasien dengan angka kejadian KTD (kejadian tidak diharapkan) sebanyak 15 kejadian, KNC (kejadian nyaris cidera) sebanyak 41 kejadian, dan KTC (kejadian tidak cidera) sebanyak 76 kejadian. Dan dari wawancara peneliti dengan sepuluh perawat di RSUD Padang Pariaman, insiden keselamatan pasien disebakan oleh sarana prasarana yang tidak memadai salah satunya sarana dalam pelaksanaan timbang terima pasien, dimana belum adanya SPO (Standar Prosedur Operasional) dan kerangka komunikasi dalam timbang terima.

Pelaksanaan timbang terima antar shift di rawat inap RSUD Padang Pariaman dilakukan berdasarkan tradisi yang sudah ada dan belum memiliki kerangka timbang terima. Informasi yang tidak lengkap dalam timbang terima dapat menyebabkan terjadi beberapa kesalahan seperti lupa memberikan terapi, tindakan keperawatan yang tidak sesuai rencana yang mengakibatkan masalah pasien tidak teratasi, kelalaian dan kesalahan sehingga kesinambungan perawatan pasien tidak berjalan sesuai prosedur. Hal ini dapat menimbulkan menimbulkan insiden keselamatan pasien. Untuk mengatasi dampak tersebut perlu ditetapkan acuan dan format timbang terima untuk memperbaiki pola timbang terima di rawat inap RSUD Padang Pariaman

Tujuan penelitian ini adalah untuk mengetahui pengaruh pelatihan komunikasi ISOBAR terhadap pengetahuan dan kualitas pelaksanaan timbang terima di RSUD Padang Pariaman

\section{METODE}

Desain penelitin ini quasy eksperimental pre test - post test with control group, yang menggambarkan pengaruh pelatihan komunikasi ISOBAR terhadap kelompok intervensi yang diberikan pelatihan dan kelompok kontrol yang tidak diberikan pelatihan. Penelitian ini dilakukan dengan cara :

1. Pada kelompok intervensi : dilakukan Pengambilan data pre test kualitas pelaksanaan operan tanggal 25 april - 2 mei 2019, sedangkan pengetahuan 
tentang komunikasi ISOBAR tanggal 04 mei 2019 sebelum pelatihan diberikan. Pelatihan diberikan dengan cara seminar, role play. Kemudian dilanjutkan dengan bimbingan tanggal 6 - 21 mei 2019 pada setiap pergantiang shift dinas pagi - siang malam. Dalam satu hari peneliti melakukan bimbingan kepada tiga responden. Setelah proses bimbingan kemudian peneliti melakukan post-test (observasi) pelaksanaan operan sesuai dengan jadwal dinas responden tanggal 21-28 mei 2019. Pengambilan data post test pengetahuan dilakukan setelah pelatihan berakhir tanggal 04 mei 2019

2. Pada Kelompok kontrol dilakukan Pengambilan data pre test (observasi) kualitas pelaksanaan tanggal 19 sampai 24 april 2019 dan pengetahuan tanggal 05 mei 2019. Kelompok kontrol tidak diberikan intervensi pelatihan. Post-test pengetahuan dan kualitas pelaksanaan operan tanggal 29 mei - 3 juni 2019 sesuai dengan jadwal responden

Penelitian ini dilakukan pada semua ketua tim perawat dan penanggung jawab shift di rawat inap RSUD Padang Pariaman sebanyak 23 orang untuk kelompok intervensi dan 18 orang pada kelompok kontrol. Pengambilan sampel dengan cara systematic random sampling. Uji statistik yang digunakan adalah Man-Whitney untuk melihat perbedaan antara kelompok intervensi yang diberikan pelatihan dengan kelompok kontrol yang tidak mendapatkan pelatihan.

\section{HASIL}

Pada penelitian ini sebagian besar responden berusia dewasa muda baik kelompok intervensi maupun kelompok kontrol dengan jenis kelamin mayoritas perempuan. Pendidikan responden kelompok intervensi dan kelompok kontrol masih banyak DIII keperawatan dengan masa kerja masih ada yang dibawah lima tahun. Dan 100\% kelompok intervensi dan kelompok kontrol belum pernah mendapatkan pelatihan komunikasi ISOBAR. (Tabel 1)

Tabel 1 Karakteristik Responden

\begin{tabular}{|c|c|c|c|c|}
\hline \multirow[t]{2}{*}{ Karakteristik } & \multicolumn{2}{|c|}{$\begin{array}{l}\text { Kelompok } \\
\text { Intervensi }\end{array}$} & \multicolumn{2}{|c|}{$\begin{array}{c}\text { Kelompok } \\
\text { Kontrol }\end{array}$} \\
\hline & $\mathrm{f}$ & $\%$ & $\mathrm{f}$ & $\%$ \\
\hline \multicolumn{5}{|l|}{ Usia } \\
\hline $\begin{array}{l}\text { a. Dewasa } \\
\text { Muda } \\
(18-40)\end{array}$ & 23 & 100 & 2 & 88,9 \\
\hline $\begin{array}{l}\text { b. Dewasa Tua } \\
\quad(>40)\end{array}$ & 0 & 0 & 0 & 11,1 \\
\hline \multicolumn{5}{|l|}{ Jenis Kelamin } \\
\hline a. Laki-laki & 1 & 4,3 & 0 & 0 \\
\hline b. Perempuan & 22 & 95,7 & 18 & 100 \\
\hline \multicolumn{5}{|l|}{ Pendidikan } \\
\hline $\begin{array}{l}\text { a. DIII } \\
\text { Keperawata } \\
n\end{array}$ & 13 & 56,5 & 13 & 72,2 \\
\hline b. S1+ Ners & 10 & 43,5 & 5 & 27,8 \\
\hline \multicolumn{5}{|l|}{ Lama Bekerja } \\
\hline $\begin{array}{l}\text { a. } \leq 5 \text { tahun } \\
\text { b. } \geq 5 \text { tahun }\end{array}$ & $\begin{array}{c}8 \\
15\end{array}$ & $\begin{array}{l}34,8 \\
65,2\end{array}$ & $\begin{array}{c}6 \\
12\end{array}$ & $\begin{array}{l}33,3 \\
66,7\end{array}$ \\
\hline \multicolumn{5}{|l|}{ Pelatihan } \\
\hline a. Ya & 0 & 0 & 0 & 0 \\
\hline c. Tidak & 23 & 100 & 18 & 100 \\
\hline
\end{tabular}

Tabel 2 Perbedaan rentang skor Pengetahuan dan Kualitas Pelaksanaan Timbang terima Sebelum dan Sesudah Pelatihan (kelompok intervensi)

\begin{tabular}{ccc}
\hline \multirow{1}{*}{ Variabel } & \multicolumn{2}{c}{$\begin{array}{c}\text { Kelompok } \\
\text { Intervensi }\end{array}$} \\
\cline { 2 - 3 } & Median & Min-Max \\
\hline Pengetahuan & & \\
Pre-Test & 8,00 & $3-10$ \\
$\quad$ Post-Test & 10,00 & $7-13$ \\
Kualitas & & \\
Pelaksanaan & & \\
Timbang terima & & \\
$\quad$ Pre-Test & 4,00 & $2-7$ \\
Post-Test & 15,00 & $12-15$ \\
\hline
\end{tabular}

Pada kelompok intervensi didapatkan rentang skor pengetahuan sebelum pelatihan dengan skor terendah 3 dan tertinggi 10 dan median 8,00. Setelah diberikan pelatihan rentang skor 
pengetahuan mengalami kenaikan dengan skor terendah 7 dan tertinggi 13 dan median 10,00. Untuk kualitas pelaksanaan timbang terima rentang skor sebelum pelatihan antara 2 dengan 7 dan median 4,00. Setelah diberikan pelatihan rentang skor kualitas pelaksanaan timbang terima neik menjadi 12 sampai 15 dan median 15,00 (Tabel 2).

Tabel 3 Perbedaan rentang skor skor Pengetahuan dan Kualitas Pelaksanaan Timbang terima Sebelum dan Sesudah Pelatihan (kelompok Kontrol)

\begin{tabular}{lcc}
\hline \multirow{2}{*}{ Variabel } & \multicolumn{2}{c}{ Kelompok Kontrol } \\
\cline { 2 - 3 } & Median & $\begin{array}{c}\text { Min- } \\
\text { Max }\end{array}$ \\
\hline Pengetahuan & & \\
Pre-Test & 6,00 & $4-9$ \\
$\quad$ Post-Test & 6,00 & $5-9$ \\
Kualitas & & \\
Pelaksanaan & & \\
Timbang terima & & \\
$\quad$ Pre-Test & 5,00 & $2-7$ \\
$\quad$ Post-Test & 5,00 & $3-7$ \\
\hline
\end{tabular}

Sementara pada kelompok kontrol tidak mengalami kenaikan rentang skor pengetahuan dan kualitas pelaksanaan timbang terima sebelum dan sesudah pelatihan. Rentang skor pengetahuan kelompok kontrol sebelum 4 sampai 9 dan setelah antara 5 sampai 9. Rentang skor kualitas pelaksanaan timbang terima sebelum antara 2 sampai 7 dan setelah antara 3 sampai 7 , dengan median yang sama yaitu 6 dan 5 (Tabel 3). Hal ini menujukkan ada perbedaan rentang skor pengetahuan pada kelompok intervensi yang diberi pelatihan dengan kelompok kontrol yang tidak mendapatkan pelatihan.
Tabel 4 Perbedaan Pengetahuan dan Pelaksanaan Timbang terima antara Kelompok Intervensi dan Kelompok Kontrol

\begin{tabular}{lccc}
\hline Variabel & Kelompok & Median & p value \\
\hline Pengetahuan & Intervensi & 2,00 & \multirow{2}{*}{0,000} \\
& Kontrol & 0,00 & \\
Pelaksanaan & Intervensi & 10,00 & \\
Timbang & Kontrol & 0,00 & 0,000 \\
terima & & & \\
\hline
\end{tabular}

Pada Tabel 4 dapat dilihat perbedaan pengetahuan ( $\mathrm{p}$ value 0,000 ) dan kualitas pelaksanaan timbang terima ( $\mathrm{p}$ value 0,000 ) antara kelompok intervensi dengan kelompok Dari hasil diatas dapat disimpulkan bahwa ada perbedaan pengetahuan dan kualitas pelaksanaan timbang terima antara kelompok intervensi yang diberi pelatihan dengan kelompok kontrol yang tidak diberi pelatihan.

\section{PEMBAHASAN}

Mayoritas umur responden kelompok intervensi dan kontrol terbanyak pada rentang 18- 40 ( dewasa muda), dimana pada rentang umur tersebut sangat mampu untuk mengikuti pelatihan dan mengaplikasikannya pada tatanan pelayanan keperawatan. Menurut (Robbins \& Judge, (2008) mengemukakan bahwa seseorang dengan umur yang lebih muda akan lebih mudah untuk memahami atau menguasai ilmu baru, sehingga pengetahuan komunikasi ISOBAR akan meningkat dengan diberikannya pelatihan.

Jenis kelamin responden hampir 100\% perempuan, dimana perawat sangat identik dengan perempuan atau ibu yang lebih dikenal dengan mother instinct (Potter, $\mathrm{P}$. A., \& Perry, 2016). Pada saat manusia baru lahir orang yang pertama kali merawat anak adalah seorang perempuan, mereka diberi kelebihan kepekaan emosi dan bekerja atas dasar naluri kepedulian pada orang lain. Oleh karena itu perawat sangat identik dengan perempuan dan sesuai 
dengan hasil penelitian yang didapat di RSUD Padang Pariaman.

Pendidikan responden kelompok kontrol dan intervensi ada pada level DIII keperawatan dan S1+Ners. Pengetahuan berhubungan dengan proses penerimaan informasi, dimana semakin tinggi tingkat pendidikan semakin tinggi pula tingkat peneriamaan informasi. Hal ini sesuai dengan yang dikemukakan Robbins dimana semakin tinggi tingkat pendidikan seseorang, maka semakin baik pula dalam menerima informasi. Masa kerja responden sebagian besar lebih dari lima tahun, namun $100 \%$ responden belum mendapatkan pelatihan. Keterampilan bisa didapatkan melalui pelatihan, untuk itu perlu diberikan pelatihan komunikasi ISOBAR terhadap responden untuk meningkatkan pengetahuan, wawasan dan keterampilan dalam pelaksanaan komunikasi saat timbang terima.

Penelitian yang telah dilakukan pada kelompok intervensi dan kelompok kontrol di RSUD Padang Pariaman didapatkan pengetahuan responden sebelum diberikan pelatihan masih ada yang mendapatkan skor rendah pada kelompok intervensi dengan skor 3, 4 dan 5 (responden no 20, 21 dan 12 ), dan responden kelompok kontrol dengan skor 4 dan 5 (responden no 2, 5, 8, 9 dan 18 ).

Analisis kuisioner pengetahuan tentang komunikasi ISOBAR dan hasil observasi pelaksanaan timbang terima didapatkan bahwa responden masih kurang paham tentang poin situation dan assesment. Responden mendapatkan nilai terendah pada kedua poin diatas. Hal ini menunjukkan bahwa responden masih kurang paham tentang komunikasi ISOBAR. Komponen ISOBAR yang akan disampaikan belum bisa dibedakan oleh responden, seperti pada komponen Identify (tentang identitas pasien), Situation (keluhan dan kondisi terkini dari pasien), Observation (hasil observasi dari kondisi pasien), Background (latar belakang kondisi pasien), Asessment (perencanaan dari penilaian kondisi pasien dari hasil pengkajian dan pemeriksaan penunjang), Recomendation (pengualngan/ memastikan informasi yang disampaikan tentang tindak lanjut dari perawatan pasien).

Menurut Febrianti, (2015) pelatihan merupakan kegiatan proses belajar untuk menigkatkan keterampilan. Arsanam et al, (2014) juga mengemukakan bahwa pelatihan meruapakan kegiatan untuk mengurangi kesenjangan keterampilan staf dengan apa yang dikehendaki perusahaan dan untuk meningkatkan kompetensi staf. Dengan demikian pelatihan dapat meningkatkan pengetahuan dan keterampilan petugas dalam melakukan komunikasi ISOBAR.

Peningkatan pengetahuan setelah diberikan pelatihan menunjukkan bahwa pelatihan dapat menambah wawasan responden tentang komunikasi ISOBAR. Hal ini sejalan dengan penelitian Beament et al, (2018) dimana pengetahuan responden tentang komunikasi ISOBAR meningkat dari 2,54 menjadi 4,32 setelah dilakukan intervensi pendidikan. Abate \& VanGraafeiland (2019) juga mengemukakan bahwa intervensi pelatihan dapat meningkatkan pengetahuan perawat, serta meningkatkan keterampilan dan sikap perawat (Sudiarta, et all 2019). Jadi pelatihan yang diberikan dalam penelitian ini dengan metode seminar, role play dan bimbingan sangat efektif dalam meningkatkan pengetahuan dan keterampilan responden.

Meningkatnya pengetahuan responden dapat meningkatkan kualitas pelaksanaan timbang terima. Hal ini sejalan dengan penelitian Beament et al, (2018) di Rumah Sakit Umum Australia dimana terdapat pengaruh pelatihan tool ISOBAR dalam pelaksanaan timbang terima dengan $\mathrm{p}=0,000$. Jadi pelatihan yang dilakukan dapat meningkatkan kualitas pelaksanaan timbang terima sehingga meningkatkan kualitas informasi yang disampaikan. 
Meningkatnya kualitas pelaksanaan timbang terima sangat menunjang dalam keselamatan pasien, dimana timbang terima yang dilakukan lebih terarah, terstruktur dan lengkap, sehingga mengurangi kesalahan - kesalahan yang akan terjadi. Dalam Blyth, et all (2017) mengatakan bahwa intervensi format timbang terima di Rumah Sakit dapat meningkatkan fokus yang dilakukan dalam timbang terima dan meminimalisir kesalahan yang terjadi. Begitu juga Geddes et al, (2016) mengemukakan bahwa komunikasi ISOBAR merupakan teknik timbang terima yang mendukung keselamatan pasien.

Komunikasi ISOBAR merupakan pengembangan dari formulir SBAR yang dikembangkan oleh tim WACHS (Western Australian Country Handover Service). Dalam kerangka komunikasi ISOBAR telah digabung menjadi satu kerangka komunikasi mulai dari melakuan identifikasi pasien, melaporkan kondisi terkini, hasil observasi, latar belakang masalah pasien, penilaian terhadap kondisi pasien dan rekomendasi tindakan serta konfirmasi informasi yang disampaikan. McGowan et al, (2014) mengemukakan penggunaan format timbang terima yang terstruktur dapat meningkatkan efisiensi informasi yang disampaikan dalam mendukung kelanjutan asuhan pasien.

Timbang terima merupakan salah satu cara dalam menyampaikan dan menerima laporan yang berkaitan dengan keadaan pasien yang dilakukan seefektif mungkin (Triwibowo et al, 2016). Dalam Merten et al, (2017) mengemukakan bahwa timbang terima adalah transfer tanggung jawab profesioal atas semua aspek keperawatan pasien. Jadi kagiatan timbang terima dalam pelayanan keperawatan merupakan salah satu rangkaian kegiatan dalam menyampaikan dan menerima pertanggung jawaban pasien sehingga kelanjutan perawatan pasien dapat berjalan sempurna serta menjaga keselamatan pasien.

Dari hasil uji statistik perbedaan pengetahuan dan pelaksanaan timbang terima pada kelompok intervensi dan kelompok kontrol dengan uji Man-Whitney didapatkan ada perbedaan pengetahuan ( $\mathrm{p}$ value 0,000), dan kualitas pelaksanaan timbang terima (p-value 0,000) antara kelompok intervensi yang mendapatkan pelatihan dengan kelompok kontrol yang tidak mendapatkan pelatihan. Sejalan dengan Penelitian Sudiarta et al, (2019) didapatkan adanya perbedaan pengetahuan perawat klinis $(\mathrm{p}=0,000)$, pelaksanaan timbang terima $(\mathrm{p}=0,000)$ dan sikap $(\mathrm{p}=0,000)$ antara kelompok intervensi dan kelompok kontrol, hal ini menunjukkan pelatihan berupa seminar, role play dan bimbingan dapat meningkatkan pemahaman perawat tentang komunikasi ISOBAR.

Metode pelatihan yang diberikan pada kelompok intervensi berupa seminar, role play dan bimbingan merupakan penggabungan beberapa metode pelatihan yang dapat meningkatkan kompetensi dan kualitas petugas, sehingga dalam pemberian pelayanan akan lebih baik dan maksimal sesuai dengan pengetahuan yang dimiliki petugas. Seminar yang diberikan akan menambah wawasan responden tentang komunikasi ISOBAR, dan role play berupa praktek langsung akan meningkatkan keterampilan responden. Sejalan dengan penelitian Lilis, (2015) dimana metode role play dapat meningkatkan keterampilan dan kemampuan peserta dalam mengaplikasikan pengetahuan yang didapat. Begitu juga dengan Neupane, (2019) mengatakan bahwa teknik role play mempengaruhi keterampilan sesorang.

Disamping seminar dan role play juga dilakukan bimbingan terhadap responden kelompok intervensi. Dengan Bimbingan responden akan lebih paham tentang komunikasi ISOBAR dan pelaksanaan timbang terima dapat dilakukan sebaik mungkin. Sejalan sejalan dengan penelitian Maharani et al, (2018) bahwa teknik bimbingan dapat meningkatkan keterampilan dan tindakan seseorang. 
Pemberian pelatihan kepada responden bertujuan untuk meningkatkan produktivitas petugas baik kuantitas maupun kualitas, sehingga bisa meningkatkan kemandirian dalam melaksanakan tugas, menambah kreatifitas, menambah stabilitas dan keluwesan organisasi sehingga rumah sakit dapat menyesuaikan diri dengan perubahan yang terjadi karena kemampuan anggota sudah merata. misal, jika ada anggota yang keluar, anggota lain bisa menggantikan karena sudah punya kemampuan yang sama. Dengan diberikannya pelatihan dapat meningkatkan semangat kerja karena dilengkapi dengan pengetahuan, keterampilan dan kemapuan yang cukup.

Fereshteh et al,(2016) mengemukakan bahwa pelatihan berguna dalam pengembangan karier jangka panjangan, membantu dalam menghadapi tanggung jawab yang besar serta meningkatkan kualitas organisasi. Program pelatihan tidak hanya bermanfaat terhadap karyawan, namun juga bermanfaat terhadap rumah sakit, dimana dengan bertambahnya pengetahuan petugas dapat memberikan layanan yang lebih baik, sehingga dapat meningkatkan kualiats rumah sakit dimata konsumen. Program pelatihan dan pengembangan merupakan kegiatan yang dapat dijadikan investasi dalam hal sumber daya manusia untuk meningkatkan kualitas rumah sakit.

Oleh karena itu bedasarkan temuan, teori dan hasil penelitian yang dilakukan, maka peneliti mengharapkan pada pihak Rumah Sakit dapat menerapkan komunikasi ISOBAR sebagai kerangka acuan dalam pelaksanaan timbang terima antar shift di RSUD Padang Pariaman. Menetapkan komunikasi ISOBAR sebagai standar komunikasi dalam melakukan timbang terima, sebagai upaya meningkatkan kualitas SDM dan kualitas layanan di Rumah Sakit. Asuhan pasien dapat diberikan sesuai prosedur dan kebutuhan, serta mengurangi resiko keselamatan pasien.

\section{KESIMPULAN}

Berdasarkan penelitian tentang pengaruh pelatihan komunikasi ISOBAR terhadap pengetahuan dan kualitas pelaksanaan timbang terima di RSUD Padang Pariaman didapatkan bahwa pelatihan komunikasi ISOBAR dengan teknik seminar, role play dan bimbingan berpengaruh terhadap kelompok intervensi, dimana timbang terima yang dilakukan lebih terstruktur dan terarah yang dapat mengurangi kesalaha dalam pelaksanaan timbang terima.

Diharapkan pihak Rumah Sakit dapat menerapkan komunikasi ISOBAR dalam pelaksanaan timbang terima. Dan begi peneliti selanjutnya dapat melakukan penelitian tentang komunikasi ISOBAR dengan metode atau variabel yang berbeda.

\section{UCAPAN TERIMA KASIH}

Peneliti mengucapkan terima kasih kepada responden di RSUD Padang Pariaman yang telah berpartisipai dalam penelitian ini dan Fakultas Keperawatan Universitas Andalas yang telah memberikan kesempatan pada peneliti dalam mengaplikasikan ilmu.

\section{DAFTAR PUSTAKA}

Abate, B., \& VanGraafeiland, B. (2019). Improving Education and Communication in an Assisted Living Facility to Reduce Avoidable Emergency Department Transfers: A Quality Improvement Project. Journal of Gerontological Nursing, 45(5), $23-$ 29. https://doi.org/10.3928/0098913420190404-01

Abdurrahman, M., \& Garcia, C. (2016). Safe clinical handover. In On-Call Geriatric Psychiatry: Handbook of Principles and Practice (pp. 87-97). https://doi.org/10.1007/978-3-31930346-8_9 
Agency for Healthcare Research and Quality (AHRQ). (2014). Hospital Survey on Patient Safety Culture. https://doi.org/10.1097/PTS.0b013e31 $81 \mathrm{~b} 53 \mathrm{f} 6 \mathrm{e}$

Arsanam, P., \& Yousapronpaiboon, K. (2014). The Relationship between Service Quality and Customer Satisfaction of Pharmacy Departments in Public Hospitals. International Journal of Innovation, Management and Technology, 5(4), 261-265. https://doi.org/10.7763/IJIMT.2014.V 5.524

Australian Commission on Safety and Quality in Healthcare. (2012). Clinical Handover Standard 6. Natl. Saf. Qual. Heal. Serv. Stand.

Beament, T., Ewens, B., Wilcox, S., \& Reid, G. (2018). A collaborative approach to the implementation of a structured clinical handover tool (iSoBAR), within a hospital setting in metropolitan Western Australian: A mixed methods study. Nurse Education in Practice, 33, 107-113. https://doi.org/10.1016/j.nepr.2018.08 .019

Blyth, C., Bost, N., \& Shiels, S. (2017). Impact of an education session on clinical handover between medical shifts in an emergency department: A pilot study. EMA - Emergency Medicine Australasia, 29(3), 336341. https://doi.org/10.1111/17426723.12717

Compton, J., Copeland, K., Flanders, S., Cassity, C., Spetman, M., Xiao, Y., \& Kennerly, D. (2012). Implementing SBAR across a large multihospital health system. Joint Commission Journal on Quality and Patient Safety, 38(6), 261-268. https://doi.org/10.1016/S15537250(12)38033-1

Eggins, S., \& Slade, D. (2015).
Communication in Clinical Handover: Improving the Safety and Quality of the Patient Experience. J Public Health Res, 4. https://doi.org/doi: 10.4081/jphr.2015.666

Febrianti, P. Y. (2015). Analisis Pengaruh Pelatihan Terhadap Peningkatan Kemampuan PNS Di Balai PU Wilayah I Medan. http://repository.usu.ac.id/handle/123 $456789 / 57747$.

Fereshteh, F., Hossein, E. A., \& Shayan, H. (2016). Evaluating of Training and Internship Programs of University Hospitals. Health, 8(4), 658-663. https://doi.org/10.4236/health.2016.87 069

Geddes, F., Della, P., Stewart-Wynne, E., \& Jones, D. (2016). 10. iSoBar: An innovative framework and checklist for clinical rounds in an interprofessional student training ward. In Effective Communication in Clinical Handover. https://doi.org/10.1515/97831103790 44-018

Güneş, Ü. Y., Gürlek, Ö., \& Sönmez, M. (2016). A survey of the patient safety culture of hospital nurses in Turkey. Collegian, 23(2), 225-232. https://doi.org/10.1016/j.colegn.2015. 02.005

KARS. (2017). Efektif 1 Januari 2018. Standar Nasional Akreditasi Rumah Sakit (Vol. 1).

Lee, J. Y. (2015). Effective communication for patient safety. Journal of the Korean Medical Association, 58(2), 100-104. https://doi.org/10.5124/jkma.2015.58. 2.100

Lilis, S. (2015). The Effectivenes of Role Play in Teaching Speaking. ELTIN Journal, 3(October), 106-109. 
Maharani, L., Masya, H., \& Janah, M. (2018). Peningkatan Keterampilan Sosial Peserta Didik SMA Menggunakan Layanan Bimbingan Kelompok Dengan Teknik Diskusi. KONSELI: Jurnal Bimbingan Dan Konseling (E-Journal), 5(1), 65. https://doi.org/10.24042/kons.v5i1.26 58

Mardis, M., Davis, J., Benningfield, B., Elliott, C., Youngstrom, M., Nelson, B., ... Riesenberg, L. A. (2015). Shift-to-Shift Handoff Effects on Patient Safety and Outcomes: A Systematic Review. American Journal of Medical Quality: The Official Journal of the American College of Medical Quality. https://doi.org/10.1177/10628606156 12923

McGowan, M., McClean, A., Verma, R., \& Anandarajan, M. (2014). Improving Patient Safety In Paediatric Handovers. Archives of Disease in Childhood, 99(Suppl 2), A571.1A571.

https://doi.org/10.1136/archdischild2014-307384.1596

Merten, H., van Galen, L. S., \& Wagner, C. (2017). Safe handover Hanneke Merten researcher in quality and safety in healthcare. BMJ, 359. https://doi.org/10.1136/bmj.j4328

National Clinical Effectiveness Commitee. (2014). Communication (Clinical Handover) in Maternity Services. Department of Health.

Neupane, B. (2019). Effectiveness of Role Play in Improving Speaking Skill. Journal of NELTA Gandaki, 1, 11-18. https://doi.org/10.3126/jong.v1i0.244 54

Porteous, J., Stewart-Wynne, E., Connolly, M., \& Crommelin, P. (2009). iSoBAR - a concept and handover checklist: the National Clinical Handover
Initiative | Medical Journal of

Australia. Med J Aust, 190(11), 152.

Retrieved from

https://www.mja.com.au/journal/2009

/190/11/isobar-concept-and-handoverchecklist-national-clinical-handoverinitiative\%5Cnhttps://www.mja.com.a u/system/files/issues/190_11_010609/ con11210_fm.pdf

Potter, P. A., \& Perry, A. G. (2016). Fundamental ofnursing concept, process and practice (9th ed). Christ Church University Canterbury: St Louis: Mosby Company.

Putra, A. J. (2013). Analisa Faktor-Faktor yang Berhubungan dengan Keselamatan Pasien (Patient Safety) di Ruang Perawatan Rumah Sakit Haji Jakarta. Kesehatan Masyarakat, $1-17$.

Robbins, S. P., \& Judge, T. A. (2008). Perilaku Organisasi Jilid II. Salemba Empat. https://doi.org/10.1097/ACM.0b013e $31821 \mathrm{db} 670$

Sohi, D., Scotney, E., Sowerbutts, H., Barber, T., \& V Rao2. (2015).

Significantly improving the efficiency of communication in paediatrics. $B M j$, 96(1).

https://doi.org/doi.org/10.1136/adc.20 11.212563.210

Sudiarta, I. K., Tarigan, E., \& Supardi, S. (2019). Effect of Nursing Training on Improving Knowledge, Skills, and Attitudes of Clinical Nurses. Indonesian Journal of Health Research, 2(1), 31-38. https://doi.org/10.32805/ijhr.2019.2.1. 42

Triwibowo, C., Yuliawati, S., \& Amri Husna, N. (2016). Handover Sebagai Upaya Peningkatan Keselamatan Pasien ( Patient Safety) di Rumah Sakit. Jurnal Keperawatan Soedirman, 11, 5. 
NERS: Jurnal Keperawatan, Volume 15, No. 2, Oktober 2019, (Hal. 92-102)

Wheeler, K. K. (2015). Effective handoff communication. Nursing Critical Care, 10(6), 13-15.

https://doi.org/10.1097/01.CCN.0000 472849.85679.c4 